\title{
Individual differences in anxiety trajectories from Grades 2 to 8: Impact of the middle school transition
}

\author{
STEFANIE A. NELEMANS, ${ }^{a}$ WILLIAM W. HALE III, ${ }^{a}$ SUSAN J. T. BRANJE, ${ }^{a}$ WIM H. J. MEEUS,${ }^{a, b}$ AND \\ KAREN D. RUDOLPH ${ }^{c}$ \\ ${ }^{a}$ Utrecht University; ${ }^{b}$ Tilburg University; and ${ }^{c}$ University of Illinois at Urbana-Champaign
}

\begin{abstract}
This study examined the impact of the middle school transition on general anxiety trajectories from middle childhood to middle adolescence, as well as how youths' individual vulnerability and exposure to contextual stressors were associated with anxiety trajectories. Participants were 631 youth $(47 \%$ boys, $M$ age $=$ 7.96 years at Time 1), followed for 7 successive years from second to eighth grade. Teachers reported on youths' individual vulnerability to anxiety (anxious solitude) in second grade; youth reported on their anxiety in second to eighth grade and aspects of their social contexts particularly relevant to the school transition (school hassles, peer victimization, parent-child relationship quality, and friendship quality) in sixth to eighth grade. The results revealed two subgroups that showed either strongly increasing (5\%) or decreasing (14\%) levels of anxiety across the transition and two subgroups with fairly stable levels of either high (11\%) or low (70\%) anxiety over time. Youth in the latter two subgroups could be distinguished based on their individual vulnerability to anxiety, whereas youth with increasing anxiety reported more contextual stressors and less contextual support than youth with decreasing anxiety. In sum, findings suggest that the middle school transition has the potential to alter developmental trajectories of anxiety for some youth, for better or for worse.
\end{abstract}

Anxiety can be defined as a multicomponent response system involving affective, cognitive, behavioral, and physiological processes that are activated when we foresee potential (i.e., uncertain or unpredictable) future danger or threat or potentially overwhelming or uncomfortable situations (Barlow, 2002). Anxiety symptoms are one of the most prevalent forms of psychopathology during childhood and adolescence (Costello, Mustillo, Erkanli, Keeler, \& Angold, 2003; Merikangas et al., 2010) and are associated with impairment in many domains of functioning (e.g., Bögels \& Brechman-Toussaint, 2006; Ialongo, Edelsohn, Werthamer-Larsson, Crockett, \& Kellam, 1995; Kingery, Erdley, Marshall, Whitaker, \& Reuter, 2010). Although anxiety symptoms are characterized by moderate stability from childhood to adolescence (Bosquet \& Egeland, 2006), perhaps due in part to temperamental inclinations toward anxiety (e.g., Biederman, Rosenbaum, Chaloff, \& Kagan, 1995; Hirshfeld-Becker, Biederman, \& Rosenbaum, 2004), significant contextual changes may differentiate anxiety trajectories.

This research was funded by a University of Illinois Arnold O. Beckman Award and National Institute of Mental Health Grant MH68444 (to K.D.R.). We thank the families and schools who participated in this study. We are grateful to Jamie Abaied, Monica Agoston, Hannah Banagale, Megan Flynn, Ellie Hessel, Nicole Llewellyn, Michelle Miernicki, Jo Pauly, Jennifer Monti, and Niwako Sugimura for their assistance in data collection and management.

Address correspondence and reprint requests to: Stefanie A. Nelemans, Research Centre Adolescent Development, Utrecht University, PO box 80.140, 3508 TC, Utrecht, The Netherlands; E-mail: s.a.nelemans@uu.nl.
The goals of this study were (a) to examine the impact of the middle school transition on the continuity versus discontinuity of anxiety over time, (b) to determine whether individual vulnerability (i.e., a tendency toward anxious solitude) early in elementary school (in second grade) distinguished youths' anxiety trajectories, and (c) to differentiate youths' anxiety trajectories based on specific qualities of youths' social contexts (i.e., stressful vs. supportive) during middle school. Because the middle school transition, like all major life transitions, requires behavioral reorganization to adapt to new biological, psychological, and social challenges (Graber \& Brooks-Gunn, 1996; Rutter, 1996), it may be characterized by a certain degree of unpredictability or ambiguity that may trigger feelings of potential danger or threat (i.e., anxiety). At the same time, the middle school transition may be an opportunity for positive change as well (as suggested by Shell, Gazelle, \& Faldowski, 2014). It is therefore important to study the impact of the middle school transition on anxiety trajectories from childhood to adolescence. Gaining such insight will contribute to a better understanding of developmental continuities and discontinuities as well as processes of risk and resilience.

\section{Youth Anxiety Trajectories and the Middle School Transition}

A growing body of literature describes the normative developmental course of anxiety symptoms in childhood (e.g., Olatunji \& Cole, 2009; Snyder et al., 2009) and adolescence (e.g., Hale, Raaijmakers, Muris, Van Hoof, \& Meeus, 2008; 
Nelemans et al., 2014; Van Oort, Greaves-Lord, Verhulst, Ormel, \& Huizink, 2009), as well as individual differences in anxiety trajectories within childhood (e.g., Broeren, Muris, Diamantopoulou, \& Baker, 2013; Duchesne, Larose, Vitaro, \& Tremblay, 2010; Feng, Shaw, \& Silk, 2008) and adolescence (e.g., Allan et al., 2014; Letcher, Sanson, Smart, \& Toumbourou, 2012; Morin et al., 2011; Nelemans et al., 2014). Overall, these studies suggest that (a) global levels of anxiety tend to be stable or decrease as youth grow older, although different forms of anxiety show distinct normative developmental patterns; (b) there are large individual differences in anxiety trajectories (i.e., most youth show stable low levels of anxiety, whereas some show stable high, increasing, or decreasing levels of anxiety over time); and (c) girls show higher anxiety symptoms than boys and are more likely than boys to report stable high or increasing levels of anxiety over time (for a systematic review of gender differences across the life span, see McLean \& Anderson, 2009), although some studies suggest that gender differences are less pronounced in childhood than in adolescence (e.g., Broeren et al., 2013; Duchesne et al., 2010). However, empirical studies on the development of anxiety symptoms from childhood into adolescence are scarce, and existing studies (e.g., Oh et al., 2008; Prinzie, Van Harten, Deković, Van den Akker, \& Shiner, 2014) have not taken into account the potential impact of the transition from elementary to middle school on stability and change in anxiety trajectories. Hence, little is known about how this school transition, in which youth are faced with an array of new academic and social challenges and opportunities, affects anxiety trajectories from childhood into adolescence.

Addressing this gap is critical, as there are reasons to expect that the middle school transition may affect anxiety trajectories. On the one hand, this transition traditionally has been viewed as a stressful time for all youth (Simmons \& Blyth, 1987), coinciding with the start of rapid biological, psychological, cognitive, and social changes associated with the transition to adolescence (Adams \& Berzonsky, 2005; Brown \& Larson, 2009; Laursen \& Collins, 2009; Simmons, Burgeson, Carlton-Ford, \& Blyth, 1987). Based on this view, (temporary) increases in anxiety symptoms may be expected for youth shortly after the transition as they are likely to experience some degree of uncertainty in this time of major change and may feel somewhat overwhelmed or uncomfortable in their new school context or social relationships. On the other hand, many modern psychological theories emphasize individual variability in youths' adjustment to major changes in roles and settings. Some youth may be better able to cope with the major changes that characterize the middle school transition and the transition into adolescence; thus, youth may show large individual differences in their feelings of anxiety across and after the transition. According to this view, the middle school transition may be a "turning point" rather than a universal time of stress (Graber \& BrooksGunn, 1996; Rutter, 1996; Seidman \& French, 2004) such that the transition may alter anxiety trajectories for better or for worse, depending on how youth navigate through this transition. Hence, the first goal of this study was to examine the impact of the middle school transition on anxiety trajectories from childhood to adolescence.

\section{Predictors of Continuity Versus Discontinuity in Youth Anxiety Trajectories}

According to the developmental psychopathology perspective, development is affected by several factors within the individual and nested contexts, which may result in continuity or discontinuity in life course trajectories (Cicchetti \& Rogosch, 2002). The principles of equifinality and multifinality are considered central for conceptualizing developmental trajectories (Cicchetti \& Rogosch, 1996). Specific to youth anxiety trajectories, equifinality suggests that youth with different levels of anxiety at any point in time may develop similar levels of anxiety across time, whereas multifinality suggests that youth with comparable levels of anxiety at any point in time may develop very different levels of anxiety across time. In line with this perspective, Weems (2008) suggests that youth can follow one of several different anxiety trajectories based on the contribution of several factors, including individual vulnerability to anxiety along with social risk and protective factors. Thus, the present research sought to examine whether individual vulnerability to anxiety in middle childhood as well as social contexts associated with the middle school transition help to differentiate youth who begin and progress along different anxiety trajectories from childhood to adolescence.

\section{Individual vulnerability in second grade and youth anxiety trajectories}

Temperamental inclinations toward anxiety constitute an important individual vulnerability factor in many etiological models of youth anxiety (e.g., Lonigan, Philips, Wilson, \& Allan, 2011; Muris, 2006; Rapee, 2002; Vasey \& Dadds, 2001). A large body of research has focused on behavioral inhibition (BI), which is characterized by shyness, withdrawal, avoidance, distress, and fear of unfamiliar people, objects, and events (Kagan, Reznick, \& Gibbons, 1989), as a temperamental vulnerability for youth anxiety symptoms early in development. Clear evidence indicates that high levels of BI constitute a risk factor for the development of anxiety symptoms in early and middle childhood (Biederman et al., 1995; Hirshfeld-Becker et al., 2004; Rosenbaum et al., 1993).

Another individual vulnerability that has been receiving increased attention over the past two decades in relation to youth anxiety symptoms is that of anxious solitude (Rubin \& Burgess, 2001). Anxious solitude is an affective-behavioral profile characterized by shyness, social hesitance, and verbal inhibition when children are among familiar peers (Gazelle \& Ladd, 2003; Gazelle \& Rubin, 2010; although children may also display these tendencies with unfamiliar peers, see Gazelle et al., 2005), and some research links early BI to later 
anxious solitude in middle childhood (Calkins \& Fox, 2002). As with BI, anxious solitude has been found to constitute an individual vulnerability for the development of anxiety symptoms in middle to late childhood (e.g., Gazelle, Workman, \& Allan, 2010). Given these empirical findings, anxious solitude may determine initial levels of anxiety in middle childhood or, in other words, the "starting point" of youths' anxiety trajectories. Hence, the second goal of this study was to determine whether anxious solitude early in elementary school could distinguish youths' anxiety trajectories.

\section{Contextual stressors and youth anxiety trajectories}

Despite clear evidence indicating that individual vulnerability is a robust predictor of youth anxiety symptoms, not all children with high levels of individual vulnerability either develop high levels of anxiety or continue to show high levels of anxiety over time, in line with the developmental psychopathology principle of multifinality. The question therefore arises under what contextual conditions youths' anxiety trajectories show either continuity or change across the middle school transition, a stage that largely coincides with the developmental transition from childhood into adolescence.

Experiences that are particularly relevant to this transition and thus may be crucial in distinguishing anxiety trajectories likely involve qualities (i.e., stressful vs. supportive) of the school environment as well as youths' relationships with peers and parents. Major organizational changes across the transition (e.g., moving from a relatively intimate elementary school setting with one main teacher to a larger, impersonal middle school setting with different teachers, classrooms, and often classmates) may result in more school-related hassles (e.g., greater workload, higher academic expectations, larger and more crowded classrooms and schools, or schedule issues) for some youth than for others. Moreover, some youth may experience social difficulties with peers (e.g., friends placed in different classes, no one to sit with at lunch, or exposure to peer victimization), whereas others may experience more social support (e.g., high-quality friendships). The same holds for quality of the parent-adolescent relationship, which is still an important predictor of adolescents' adjustment (Garnefski \& Diekstra, 1996; Helsen, Vollebergh, \& Meeus, 2000); some youth may experience more problems with their parents (e.g., high levels of conflict), whereas others may experience more social support from their parents (e.g., support of autonomy and independence or a warm parental environment; Laursen \& Collins, 2009). More stressful or less supportive contexts may exacerbate youths' feelings of uncertainty or discomfort across and after the middle school transition, which is likely to be associated with persistent high or increasing levels of anxiety. In contrast, more supportive or less stressful contexts likely attenuate such feelings, by helping youth cope with negative thoughts and emotions, encouraging approach rather than avoidance in new situations, and providing opportunities for positive growth, which is likely to be associated with persistent low or decreasing levels of anxiety.
Because youth differ in their school-related and social experiences after the middle school transition, this transition may have diverse effects on youths' anxiety trajectories. For some youth, levels of (mal)adaptation (reflected in high/low anxiety levels) prior to the middle school transition may continue to be the most important predictor of adjustment across and after the transition, predicting continuity in anxiety trajectories across the middle school transition. For other youth, stressful or supportive experiences associated with the new school setting or relationships with parents or peers may be linked to a discontinuity of anxiety trajectories (Cicchetti \& Rogosch, 1996, 2002; Weems, 2008). Specifically, increasing levels of anxiety after the transition are likely for youth who experience stressful school, peer, and family contexts, whereas decreasing levels of anxiety after the transition are likely for youth who experience supportive contexts. Hence, the third goal of this study was to examine whether specific qualities of youths' social contexts (i.e., stressful vs. supportive) during middle school were associated with youths' anxiety trajectories across the transition from elementary to middle school.

\section{The Present Study}

In sum, the goals of this longitudinal community study were threefold. First, we aimed to examine the impact of the middle school transition on developmental trajectories of anxiety symptoms from second to eighth grade (middle childhood to middle adolescence). Based on the aforementioned theories (e.g., Cicchetti \& Rogosch, 1996, 2002; Rutter, 1996; Weems, 2008) and empirical findings on anxiety development and trajectories in either childhood or adolescence, we expected that most youth would generally show low and stable levels of anxiety symptoms across time, which might fluctuate slightly or show modest declines that are attributable to normative decreases in anxiety across time, but would show relative continuity across the middle school transition. We expected that a second subgroup of youth would show relatively high and stable levels of anxiety over time, representing a high-risk group of youth burdened with persistent anxiety problems that would also show relative continuity across the middle school transition. Finally, we expected that the middle school transition could be a potential breakpoint in developmental trajectories of anxiety for some youth. This could result in increasing anxiety symptoms for some but decreasing anxiety symptoms for other youth after this transition. In line with prior research, we expected girls to be overrepresented in the anxiety trajectory groups with stable high or increasing levels of anxiety into adolescence (i.e., after the middle school transition).

Second, we aimed to determine whether individual vulnerability to anxiety (i.e., a tendency toward anxious solitude) predicted higher levels of anxiety early in elementary school. Given that individual vulnerabilities to anxiety have been suggested to play an important role in early levels of youth anxiety (e.g., Gazelle et al., 2010; Hirshfeld-Becker et al., 2004), we 
expected higher levels of anxious solitude in second grade to predict where youths' anxiety trajectories start out.

Third, we aimed to distinguish youths' anxiety trajectories based on specific qualities of youths' social contexts (i.e., stressful vs. supportive) from early to middle adolescence during middle school. In line with developmental theories (Cicchetti \& Rogosch, 1996, 2002; Muris, 2006; Vasey \& Dadds, 2001) and with studies showing strong associations between psychosocial functioning in the school, peer, and family context and adolescent anxiety symptoms (e.g., Bögels \& Brechman-Toussaint, 2006; Kingery et al., 2010; Seipp, 1991), we expected that anxiety trajectories would be distinguished by experiences in the new middle school context as well as in relationships with peers and parents throughout middle school. Specifically, we predicted that stable high or increasing anxiety trajectories would be characterized by stressful or unsupportive social contexts, whereas stable low or decreasing anxiety trajectories would be characterized by positive or supportive social contexts.

\section{Method}

\section{Participants}

Participants were 631 youths $\left(47 \%\right.$ boys, $M_{\text {age }}=7.96$ years at Wave $1, S D_{\text {age }}=0.35 ; 67 \%$ White, $22 \%$ Black, $11 \%$ other race or multiracial ${ }^{1}$ ) recruited in second grade to participate in the Social Health and Relationship Experiences project, a longitudinal study of peer relationships in the Midwest area of the United States. The sample consisted of 35\% low socioeconomic status (SES) youth (i.e., receiving subsidized school lunch), ${ }^{2}$ recruited from several small urban and rural Midwestern towns. Sample attrition was relatively low in our study; data on anxiety symptoms were available for 562 participants at second grade (89.1\% of the total sample), 585 participants at third grade ( $92.7 \%$ of the total sample), 567 participants at fourth grade ( $89.9 \%$ of the total sample), 550 participants at fifth grade (87.2\% of the total sample), 525 participants at sixth grade ( $83.2 \%$ of the total sample), 467 participants at seventh grade $(74.0 \%$ of the total sample), and 464 participants at eighth grade $(73.5 \%$ of the total sample). Youth still participating in the study at eighth grade were slightly younger, $F(1,629)=4.89, p=.03, \eta^{2}=0.01$, and

1. For the purpose of our analyses, we dichotomized youths' race into White and other.

2. Five youth were not included in our analyses due to missing data on SES. Concerning SES, we asked parents to complete a demographic form that included annual family income and parental education, but parent questionnaires were completed by mail and not all parents returned the questionnaire. Specifically, $31.9 \%$ of the data were missing on annual family income and $31.7 \%$ to $42.6 \%$ were missing on parental education at the start of the study. For those families with data, there were strong associations between receipt of subsidized school lunch and both annual family income, $F(1,428)=424.95, p<.001$, partial $\eta^{2}=0.50$, and parental education, $F(2,356)=35.63, p<.001$, partial $\eta^{2}=0.17$. This attests to the validity of receipt of subsidized school lunch as an indicator of SES. more likely to come from low-SES families, $\chi^{2}(1)=9.45, p$ $=.002$, Cramer $V=0.12$, than those dropping out of the study, but there were no significant differences in gender, $\chi^{2}(1)=0.82, p=.37$, race, $\chi^{2}(1)=0.68, p=.41$, or anxiety symptoms at the start of the study, $F(1,560)=1.83, p=.18$. All 631 participants were included in our analyses.

\section{Procedure}

In second grade, consent forms were distributed to families of 724 eligible second graders across schools in several small urban and rural Midwestern towns. Before the start of the study, parents provided written informed consent and youth provided oral assent. Of the eligible families, $80 \%(n=576)$ consented to participate. Participants and nonparticipants did not significantly differ in sex, $\chi^{2}(1)=0.15, n s$; age, $t(723)=0.63, n s$; race (White vs. other), $\chi^{2}(1)=0.59$, $n s$; or SES (receiving subsidized school lunch yes vs. no), $\chi^{2}(1)=0.35, n s$. An additional 60 third graders who were classmates of the original participants were added the following year, resulting in a total of 636 participants (see footnote 2 ). During the winter of each year from second to eighth grade, participants completed questionnaires in small groups (elementary school) or classrooms (middle school). The transition from elementary to middle school took place between fifth and sixth grade. Teacher surveys were distributed and returned at school. Youth received a small gift, and teachers received a monetary reimbursement. All procedures were approved by the Institutional Review Board of the University of Illinois at Urbana-Champaign.

\section{Measures}

Table 1 presents descriptive information on the measures.

Anxiety symptoms. From second to eighth grade, youth completed the Revised Children's Manifest Anxiety Scale (RCMAS; Reynolds \& Paget, 1981; Reynolds \& Richmond, 1979) to measure general anxiety symptoms. The RCMAS is a self-report questionnaire consisting of 28 items (e.g., "I worry a lot of the time" and "I feel that others do not like the way I do things"). Youth rated each item yes or no to indicate whether the item described them. The RCMAS has strong psychometric properties (Muris, Merckelbach, Ollendick, King, \& Bogie, 2002; Reynolds \& Paget, 1981; Reynolds \& Richmond, 1979; Seligman, Ollendick, Langley, \& Baldacci, 2004; Varela \& Biggs, 2006). Sum scores were calculated, with higher scores representing higher levels of youth anxiety ( $\alpha \mathrm{s}=0.88-0.91$ across waves).

Anxious solitude. Early in elementary school (second grade), teachers reported on youths' anxious solitude using an eightitem adapted version of the measure developed by Gazelle and Ladd (2003). Items were modified to reflect a peer context by adding a comparison (e.g., "Child plays alone more than most other children") or rewording the items (e.g., "Child is ner- 
Table 1. Means and standard deviations of all study variables $(N=631)$

\begin{tabular}{|c|c|c|c|c|c|c|c|c|c|c|c|c|c|c|}
\hline \multirow[b]{2}{*}{ Variable } & \multicolumn{2}{|c|}{ Grade 2 (T1) } & \multicolumn{2}{|c|}{ Grade 3 (T2) } & \multicolumn{2}{|c|}{ Grade 4 (T3) } & \multicolumn{2}{|c|}{ Grade 5 (T4) } & \multicolumn{2}{|c|}{ Grade 6 (T5) } & \multicolumn{2}{|c|}{ Grade 7 (T6) } & \multicolumn{2}{|c|}{ Grade 8 (T7 } \\
\hline & $M$ & $S D$ & $M$ & $S D$ & $M$ & $S D$ & $M$ & $S D$ & $M$ & $S D$ & $M$ & $S D$ & $M$ & $S D$ \\
\hline Anxiety symptoms & 11.46 & 6.76 & 10.26 & 6.49 & 9.25 & 6.74 & 8.56 & 6.97 & 8.35 & 6.62 & 7.39 & 6.50 & 7.67 & 6.27 \\
\hline $\begin{array}{l}\text { Anxious solitude } \\
\text { School hassles }\end{array}$ & 1.47 & 0.61 & & & & & & & 1.85 & 0.57 & & & & \\
\hline Peer victimization & & & & & & & & & 1.73 & 0.57 & 1.64 & 0.51 & 1.61 & 0.48 \\
\hline $\begin{array}{l}\text { Parent-child rel. } \\
\text { qual. }\end{array}$ & & & & & & & & & 3.92 & 0.69 & 3.88 & 0.66 & 3.80 & 0.72 \\
\hline Friendship qual. & & & & & & & & & 3.74 & 0.61 & 3.84 & 0.59 & 3.89 & 0.55 \\
\hline
\end{tabular}

Note: The middle school transition is between Grades 5 and 6. T1-T7, Times 1-7; rel. qual., relationship quality. Anxiety symptoms were assessed using selfreports on the Revised Children's Manifest Anxiety Scale and ranged from 0 to 28 (sum score). Anxious solitude was assessed using teacher reports on an 8-item adapted version of the measure developed by Gazelle and Ladd (2003). School hassles were assessed using self-reports on an adapted 21-item version of the School Hassles Questionnaire. Peer victimization was assessed using self-reports on a revised 21-item version of the Social Experiences Questionnaire. Parentchild relationship quality and friendship quality were assessed using self-reports on the Inventory of Parent and Peer Attachment. Anxious solitude, school hassles, peer victimization, parent-child relationship quality, and friendship quality all ranged from 1 to 5 (average score).

vous, high-strung, or tense when around other children"). All items were rated on a 5-point scale, ranging from 1 (not at all) to 5 (very much). Teacher reports on this measure have been found to correspond with peer nomination and observers' ratings of youths' anxious solitary behavior (Gazelle \& Ladd, 2003). Mean scores were calculated, with higher scores representing higher levels of anxious solitude $(\alpha=0.91)$.

School hassles. After the middle school transition (sixth grade), youth completed an adapted 21-item version of the School Hassles Questionnaire (Robinson, Garber, \& Hilsman, 1995) to report on their perceptions of daily school hassles. This measure was administered only in sixth grade as the hassles were focused on those presumed to be associated with adjusting to the middle school transition. These hassles concerned multiple aspects of the new school environment, such as academic expectations (e.g., "You have had too much homework"), school structure (e.g., "School is large and crowded"), schedule issues (e.g., "The periods between classes are too short to get to your next class on time"), and social reorganization ("Your friends from last year went to a different school or are in different classes"). All items were rated on a 5-point scale, ranging from 1 (not at all) to 5 (very much). Mean scores were calculated, with higher scores representing higher levels of school hassles $(\alpha=0.89)$.

Peer victimization. During middle school (sixth to eighth grade), youth completed a revised 21-item version (Rudolph, Troop-Gordon, Hessel, \& Schmidt, 2011) of the Social Experiences Questionnaire (Crick \& Grotpeter, 1996) to assess exposure to peer victimization. This measure assesses overt victimization (being the target of behaviors intended to harm others through physical damage or the threat of such damage; e.g., "How often do you get pushed or shoved by another kid?") and relational victimization (being the target of behaviors intended to harm others through manipulation of relationships; e.g., "How often does another kid try to keep others from liking you by saying mean things about you?").
Items were rated on a 5-point scale, ranging from 1 (never) to 5 (all the time). Scores on overt and relational victimization were combined into a total peer victimization score ( $r$ at each wave ranged from .71 to .73 ). ${ }^{3}$ Self-reports of victimization have been shown to provide valid information that corresponds to reports by peers (e.g., Graham \& Juvonen, 1998) and parents (Bollmer, Harris, \& Milich, 2006). Mean scores were calculated, with higher scores representing higher levels of peer victimization ( $\alpha \mathrm{s}=0.93-0.94$ across waves).

Friendship quality and parent-child relationship quality. During middle school (sixth to eighth grade), youth completed the Inventory of Parent and Peer Attachment (IPPA; Armsden \& Greenberg, 1987) to assess the quality of relationships with their friends and parents. The IPPA consists of 28 items to assess parent-child relationship quality (e.g., "My parents respect my feelings") and 25 items to assess friendship quality (e.g., "When we discuss things, my friends consider my point of view"). Three broad dimensions of relationship quality are assessed by the IPPA: degree of mutual trust, quality of communication, and the extent of anger and alienation experienced in the relationship. Items were rated on a 5point scale, ranging from 1 (almost never or never true) to 5 (almost always or always true). The IPPA has strong psychometric properties (Armsden \& Greenberg, 1987; Ridenour, Greenberg, \& Cook, 2006). Mean scores were calculated, with higher scores representing higher levels of parent-child relationship quality ( $\alpha \mathrm{s}=0.94-0.96$ across waves) and friendship quality ( $\alpha=0.92$ across waves).

\section{Statistical analyses}

Growth mixture modeling (GMM) in Mplus Version 7.4 (Muthén \& Muthén, 1998-2015) was used to identify subgroups of youth with different developmental trajectories

3. An identical pattern of results was found when overt and relational victimization were analyzed separately. 
of anxiety symptoms from middle childhood to middle adolescence (second grade to eighth grade). We specifically modeled the middle school transition by setting up a piecewise GMM model with two separate growth factors (i.e., slopes). The first growth factor represented anxiety development during elementary school (second to fifth grade), whereas the second growth factor represented anxiety development during middle school (sixth to eighth grade). By modeling development in this manner, we were able to capture potential abrupt changes in anxiety trajectories around the middle school transition. ${ }^{4}$ In our analyses, we controlled for potential effects of gender, race, and SES on class membership (i.e., gender, race, and SES as predictors of the probability of belonging to the different anxiety trajectory classes) as well as on the initial status and growth factors within the trajectory classes (i.e., gender, race, and SES as predictors of the anxiety level second grade and the subsequent changes in anxiety during elementary and middle school). Little's missing completely at random test showed that data were missing completely at random, $\chi^{2}(641)=668.42, p=.22$. Missing anxiety data were handled in Mplus with full information maximum likelihood (FIML; Muthén \& Muthén, 1998-2015).

We used several criteria to determine the final number of subgroups with distinct anxiety trajectories (Jung \& Wickrama, 2008; Nagin, 2005; Reinecke, 2006). First, an additional group had to result in an improvement of model fit, indicated by a decrease in the sample-size adjusted Bayesian information criterion (SSA BIC) and a significant adjusted Lo-Mendell-Rubin likelihood ratio test. Second, entropy (a standardized measure of classification quality, ranging from 0 to 1 ) had to be acceptable, with values closer to 1 indicating better classification accuracy. Third, we evaluated the interpretability of the groups. If an additional group was found to be a slight variation of a group already found in a lower class solution, we chose the most parsimonious model. Fourth, every group had to cover at least $5 \%$ of the sample for meaningful interpretation and further analysis.

To determine whether second-grade levels of anxious solitude could distinguish youths' anxiety trajectories, we used the Mplus AUXILIARY (R3STEP) approach (Asparouhov $\&$ Muthén, 2014). This approach tests anxious solitude as a predictor of the anxiety trajectories (i.e., multinomial logistic regression analysis) but takes into account the probability that each individual has of being a member of each of the identified classes (i.e., takes into account classification uncertainty/inaccuracy), rather than assigning individuals to their most likely class membership as is commonly done in multiple-step procedures. Because the AUXILIARY approach es-

\footnotetext{
4. Modeling youth anxiety trajectories using piecewise GMM models that reflected the middle school transition consistently showed better fit to the data, reflected in lower SSA BIC values and higher entropy values, across all class solutions than modeling anxiety trajectories using GMM models without specific attention to the middle school transition by specifying linear and nonlinear (i.e., quadratic) growth factors. Anxiety trajectories in the piecewise and continuous models were quite comparable, attesting to the robustness of our findings.
}

timates the GMM model separately from the prediction by anxious solitude, FIML cannot be applied to missing data in anxious solitude. Therefore, missing data on anxious solitude were imputed with expectation maximization in SPSS before the GMM analysis.

Finally, to examine whether school hassles, peer victimization, friendship quality, and parent-child relationship quality during middle school distinguished anxiety trajectories, we examined differences between the anxiety trajectory classes in these perceived qualities of youths' social contexts after the middle school transition (sixth grade; specifically concerning school hassles), throughout middle school (average of sixth to eighth grade), and at the end of middle school (eighth grade). These variables were not incorporated directly into the GMM model as predictors, but instead we used the Mplus AUXILIARY approach (Asparouhov \& Muthén, 2014) to test equality of means on these variables across the different anxiety trajectory classes while taking into account classification uncertainty/inaccuracy. Because the AUXILIARY approach estimates the GMM model separately from the equality of means test, FIML cannot be applied to missing data in qualities of youths' social contexts. Therefore, missing data on the social context variables were imputed with expectation maximization in SPSS before the GMM analysis, in the same imputation as the scores on anxious solitude. To correct for multiple testing, we calculated a corrected level of significance using the method described by Benjamini and Hochberg (1995) to control for the false discovery rate.

\section{Results}

\section{Descriptive statistics}

Table 1 provides an overview of the mean levels of the variables across the study. For the total sample, these means show a slight decrease in anxiety symptoms from second to eighth grade and a slight decrease in peer victimization and parent-child relationship quality as well as a slight increase in friendship quality from sixth to eighth grade. Depending on which clinical cutoff score we applied to identify youth experiencing levels of anxiety of clinical interest at each wave, either an overall cutoff point of 19 (Stallard, Velleman, Langsford, \& Baldwin, 2001) or at least 1 or $2 S D$ above the mean ( $\mathrm{T} \geq 60$ or $\mathrm{T} \geq 70$, respectively), $7.3 \%-16.4 \%, 15.0 \%-20.3 \%$, or $2.4 \%-6.9 \%$ of youth in our sample showed clinically significant levels of anxiety across the waves, respectively. Rank-order stability was high for all constructs that were assessed at multiple waves, with correlations between successive waves ranging from .44 to .72 for youths' anxiety symptoms, .70 to .73 for peer victimization, .69 to .73 for parent-child relationship quality, and .60 to .61 for friendship quality.

\section{Youth anxiety trajectories and the middle school transition}

Table 2 summarizes the fit statistics of all considered class solutions. Based on our selection criteria, we decided upon a 
Table 2. Model fit statistics for all growth mixture models with admissible solutions

\begin{tabular}{|c|c|c|c|c|c|c|c|c|}
\hline \multirow[b]{2}{*}{ Solution } & \multirow[b]{2}{*}{ SSA BIC } & \multirow[b]{2}{*}{ Entropy } & \multirow[b]{2}{*}{ Adj. LMR-LRT } & \multicolumn{5}{|c|}{ Class Size $(\%)$} \\
\hline & & & & 1 & 2 & 3 & 4 & 5 \\
\hline 1 class & 23089.032 & - & - & 100 & & & & \\
\hline 2 class & 23006.699 & 0.62 & 0.04 & 21 & 79 & & & \\
\hline 3 class & 22942.735 & 0.73 & 0.14 & 14 & 15 & 71 & & \\
\hline 4 class & 22893.531 & 0.77 & $<0.001$ & 5 & 14 & 11 & 70 & \\
\hline 5 class & 22895.350 & 0.70 & 0.91 & 4 & 11 & 13 & 21 & 51 \\
\hline
\end{tabular}

Note: The best-fitting class solution is in bold. SSA BIC, sample-size adjusted Bayesian information criterion; adj. LMR-LRT, adjusted Lo-Mendell-Rubin likelihood ratio test. Entropy values and the adjusted LMR-LRT test are not available for a one-class solution. Class size represents the percentage of youth within every class, based on their most likely class membership.

four-class solution as the best fitting GMM model. First, the SSA BIC showed a steady decrease from the one-class to the four-class solution but slightly increased from the four-class to the five-class solution, and the adjusted Lo-MendellRubin likelihood ratio test was significant from the three-class to the four-class solution but insignificant from the four-class to the five-class solution. Second, classification accuracy was most acceptable in the four-class solution (i.e., entropy of .77, which was slightly better than in all other class solutions), albeit somewhat on the low side. This relatively weak entropy value emphasizes the importance of our analytical approach using the Mplus AUXILIARY function to account for classification uncertainty/inaccuracy in examining associations between youths' anxiety trajectories and other aspects of psychosocial functioning. Third, the four-class solution did not include slight variations of a class already found in a lower class solution. Fourth, the five-class solution was inadmissible because we identified a class consisting of less than $5 \%$ of the youth. Because individual differences (i.e., variance) in the middle school slope were very small and nonsignificant (suggesting that within the identified classes, there were almost no individual differences in anxiety development across middle school), we fixed this parameter to zero for reasons of parsimony (which also resulted in a slightly better model fit). Table 3 gives an overview of the developmental parameters for all four classes in the final GMM model. In addition, Figure 1 graphically displays the anxiety trajectories of all four classes in the final GMM model.

As expected, the majority of youth $(70 \%)$ consistently showed relatively low levels of anxiety symptoms from second to eighth grade. In contrast, $11 \%$ of youth consistently showed relatively high levels of anxiety symptoms from second to eighth grade. These two subgroups were labeled as persistent low and persistent high anxiety trajectories, respectively. Two classes of youth showed slight decreases in anxiety symptoms during elementary school, but showed strongly diverging trajectories of anxiety after the middle school transition. Specifically, $14 \%$ of youth showed strongly decreasing levels of anxiety after the middle school transition, whereas the remaining 5\% of youth showed strongly increasing levels of anxiety after the middle school transition. These two subgroups were labeled as decreasing after transition and increasing after transition anxiety trajectories, respectively, which will be further referred to as decreasing and increasing in the main body of this article.

Youth in the persistent low anxiety class reported lower initial levels of anxiety early in elementary school (second grade) than youth in the persistent high, Wald $\chi^{2}(1)=$ 18.27, $p<.001$, increasing, Wald $\chi^{2}(1)=6.90, p<.01$, and decreasing, Wald $\chi^{2}(1)=37.08, p<.001$, anxiety classes. Youth in these latter three classes reported comparable initial levels of anxiety in second grade, Wald $\chi^{2}$ s $(1)<3.01, p s>.05$. At the end of middle school (eighth grade), youth in the persistent low and decreasing anxiety classes reported comparably low levels of anxiety, Wald $\chi^{2}$ (1) $=2.31, p=.13$, whereas youth in the persistent high and increasing anxiety classes reported comparably high levels of anxiety, Wald $\chi^{2}(1)=1.11, p=.29$. Furthermore, anxiety levels of youth in the persistent low and decreasing anxiety classes were significantly lower than anxiety levels of youth in the persistent high and increasing anxiety classes, Wald $\chi^{2}$ s $(1)>63.31, p$ s $<.001$.

Gender, ${ }^{5}$ race, and SES were included in our GMM model as covariates. ${ }^{6}$ Within the four classes in the final GMM model, girls reported marginally significantly higher initial levels of anxiety than boys $(b=0.99, \beta=0.26, p=.06)$, and youth from low-SES families reported significantly higher initial levels of anxiety than youth from higher SES families $(b=2.11, \beta=0.55, p<.001)$. Between classes, girls were marginally significantly more likely to belong to the increasing anxiety class $(b=1.05$, odds ratio $[O R]=$ $2.85, p=.06)$ and significantly more likely to belong to the persistent high anxiety class $(b=0.80, O R=2.22$,

5. We also conducted exploratory multiple-group GMM analyses, allowing for differences between boys and girls in the number and the shape of the anxiety trajectories. Results from these analyses suggested the same number of anxiety trajectories with a similar shape for both boys and girls and similar to results from our total-sample GMM analyses. Boys and girls thus appeared to show a similar pattern of individual differences in anxiety trajectories across the middle school transition.

6. Class solutions were highly similar excluding all covariates from the GMM models. 
Table 3. Adjusted estimates of the intercept and slope factors in the four-class growth mixture modeling solution

\begin{tabular}{|c|c|c|c|c|c|c|}
\hline \multirow[b]{2}{*}{ Classes } & \multicolumn{2}{|c|}{ Intercept } & \multicolumn{2}{|c|}{$\begin{array}{l}\text { Slope Elementary } \\
\text { School }\end{array}$} & \multicolumn{2}{|c|}{ Slope Middle School } \\
\hline & $M$ & $S D$ & $M$ & $S D$ & $M$ & $S D^{a}$ \\
\hline \multicolumn{7}{|l|}{ Class $1(5 \%)$} \\
\hline Increasing after transition & $13.75 * * *$ & 3.84 & $-1.42 *$ & 1.27 & $2.95 * * *$ & - \\
\hline \multicolumn{7}{|l|}{ Class $2(14 \%)$} \\
\hline Decreasing after transition & $16.43 * * *$ & 3.83 & $-0.90 \dagger$ & 1.28 & $-3.13 * * *$ & - \\
\hline \multicolumn{7}{|l|}{ Class $3(11 \%)$} \\
\hline Persistent high & $14.27 * * *$ & 3.82 & $1.69 * * *$ & 1.27 & $-1.07 * * *$ & - \\
\hline \multicolumn{7}{|l|}{ Class $4(70 \%)$} \\
\hline Persistent low & $9.41 * * *$ & 3.82 & $-1.36 * * *$ & 1.28 & 0.07 & - \\
\hline
\end{tabular}

Note: The factor loadings of the slope factors were linearly parameterized both during elementary and middle school.

${ }^{a}$ The variance of the middle school slope was fixed to zero (see the Results section).

$\dagger p<.10 . * p<.05 . * * * p<.001$.

$p=.02)$ than to the persistent low anxiety class than boys. In addition, White youth were significantly less likely to belong to the increasing anxiety class $(b=-1.40, O R=0.25, p=$ $.01)$ and marginally significantly more likely to belong to the decreasing anxiety class $(b=1.15, O R=3.14, p=.06)$ than to the persistent low anxiety class than other youth. ${ }^{7}$

\section{Individual vulnerability and youth anxiety trajectories}

Results of the multinomial logistic regression analyses using a three-step approach (Asparouhov \& Muthén, 2014) revealed that higher levels of anxious solitude, as reported by teachers at the start of the study (second grade), significantly distinguished youth in the persistent high $(b=0.59, O R=$ $1.80, p<.01, M=1.63, S E=0.08)$ and decreasing $(b=$ $0.50, O R=1.65, p=.048, M=1.57, S E=0.08)$ classes from youth in the persistent low class $(M=1.42, S E=$ $0.03)$. Youth in the increasing class $(M=1.48, S E=0.12)$ were not significantly different on anxious solitude from youth in the persistent low class $(b=0.23, O R=1.26$, $p=.56$ ). No other significant differences were found between the anxiety trajectory classes in anxious solitude at the start of the study in middle childhood (second grade). ${ }^{8}$

\section{Contextual stressors and youth anxiety trajectories}

Table 4 gives an overview of the means and standard errors of all social contextual factors within each of the four classes in the final GMM model for which equality of means between classes was tested using a three-step approach (Asparouhov \&

7. Only (marginally) significant results are reported.

8. A similar pattern of findings was found when examining pretransition mean levels of anxious solitude from second to fifth grade. Specifically, higher levels of pretransition anxious solitude significantly distinguished youth in the persistent high class from youth in the persistent low class. However, unlike second-grade anxious solitude, pretransition (second to fifth grade) anxious solitude did not significantly differ between youth in the decreasing class and youth in the persistent low class.
Muthén, 2014). Using the method described by Benjamini and Hochberg (1995), our corrected level of significance was calculated as $p<.036$ (instead of $p<.05$ ).

After the middle school transition in sixth grade, the highest levels of school hassles were reported by youth in the persistent high class, followed by youth in the increasing, decreasing, and persistent low classes. All differences in school hassles between the anxiety trajectory classes were significant $(p<.036)$, although there was a marginally significant difference between youth in the increasing and the decreasing classes, $\chi^{2}(1)=3.31, p=.069$.

Throughout middle school (sixth to eighth grade), the highest levels of peer victimization and the lowest levels of parent-child relationship quality were reported by youth in the persistent high class, followed by youth in the increasing, decreasing, and persistent low classes. Differences between the classes were all significant $(p<.036)$, except for differences between youth in the persistent high and increasing classes $(p s \geq .50) .{ }^{9}$ With respect to friendship quality throughout middle school, youth in the persistent high class reported significantly lower levels compared to the decreasing class, $\chi^{2}(1)=6.41, p=.01$, and the persistent low class, $\chi^{2}(1)=24.85, p<.001$. In addition, youth in the increasing class reported significantly lower levels of friendship quality compared to the persistent low class, $\chi^{2}(1)=5.88, p=.02$.

At the end of middle school (eighth grade), a consistent pattern of findings suggested that the highest levels of victimization and the lowest levels of parent-child relationship quality and friendship quality were reported by youth in the increasing class, followed by youth in the persistent high,

9. In our study, we collected pretransition levels of youths' perceived peer victimization but not perceived family, peer, and school contexts before their transition to middle school. Post hoc analyses including standardized residual scores correcting perceived peer victimization from sixth to eighth grade for pretransition levels of perceived peer victimization from second to fifth grade resulted in exactly the same pattern of findings based on posttransition means of perceived peer victimization without any correction. 


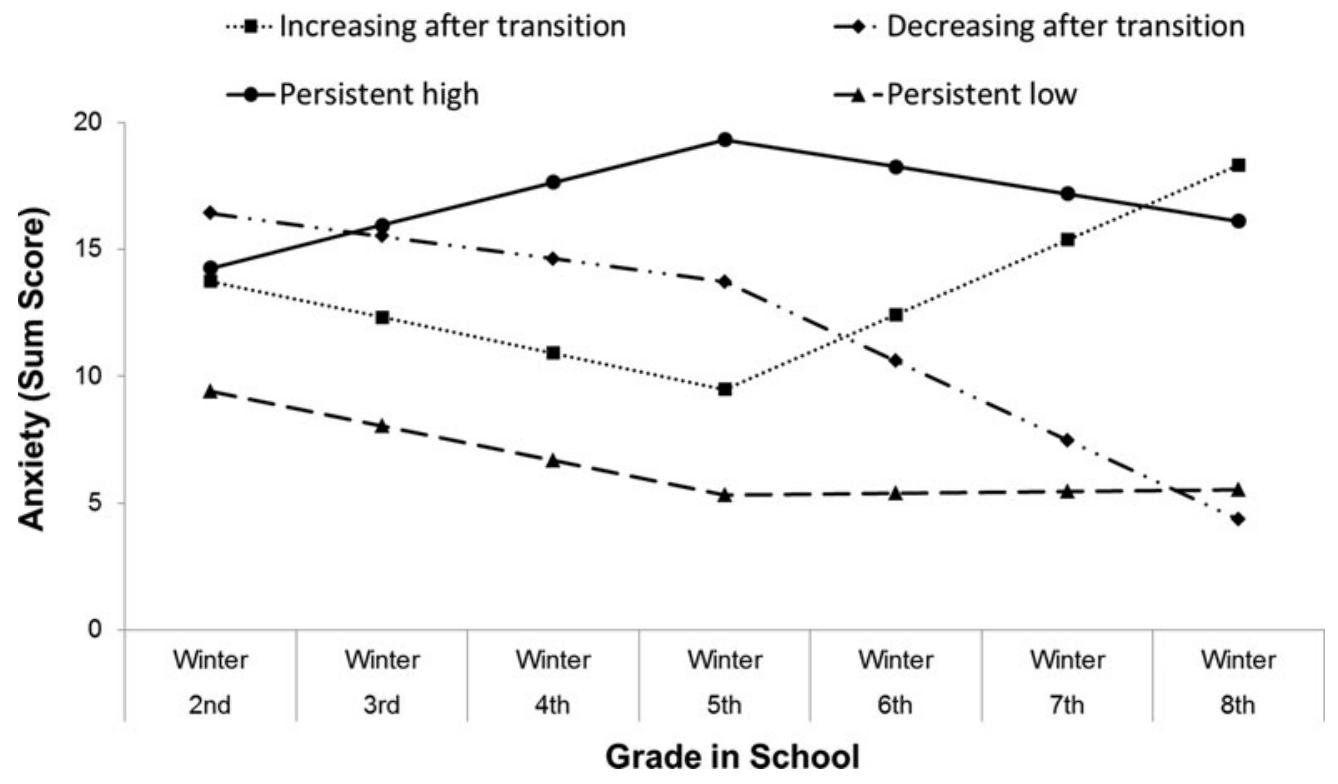

Figure 1. Graphical representation of the impact of the middle school transition (in between assessments in fifth and sixth grade) on youth anxiety trajectories for the four classes in the final growth mixture model.

decreasing, and the persistent low classes. Differences between the classes were all significant $(p<.036)$, with the exception that youth in the decreasing class reported similar levels of all constructs as youth in the persistent low class, $\chi^{2} s(1)<3.00, p s>.08$, and youth in the increasing class reported similar levels of all constructs as youth in the persistent high class, $\chi^{2} \mathrm{~s}(1)<0.45, p s>.50$.

\section{Discussion}

The present study examined the impact of the middle school transition on anxiety trajectories from middle childhood to middle adolescence (second to eighth grade) as well as whether youths' individual vulnerability and perceived exposure to contextual stressors distinguished their starting point and trajectories of anxiety after the middle school transition, respectively. Results suggested that anxiety trajectories of the majority of youth $(81 \%)$ showed continuity across the middle school transition and were characterized by fairly stable levels of either high or low anxiety symptoms throughout elementary and middle school from middle childhood to middle adolescence. These subgroups of youth could be distinguished by their levels of teacher-reported anxious solitude in middle childhood (second grade); youth with stable high anxiety

Table 4. Means and standard errors of social contextual factors in the four-class growth mixture modeling solution

\begin{tabular}{|c|c|c|c|c|c|c|c|c|}
\hline & \multicolumn{2}{|c|}{$\begin{array}{l}\text { Increasing After } \\
\text { Transition }\end{array}$} & \multicolumn{2}{|c|}{$\begin{array}{l}\text { Decreasing After } \\
\text { Transition }\end{array}$} & \multicolumn{2}{|c|}{ Persistent High } & \multicolumn{2}{|c|}{ Persistent Low } \\
\hline & $M$ & $S E$ & $M$ & $S E$ & $M$ & $S E$ & $M$ & $S E$ \\
\hline \multicolumn{9}{|l|}{ School hassles } \\
\hline Grade 6 & $2.18_{\mathrm{a}}^{a}$ & 0.14 & $1.88_{\mathrm{b}}^{a}$ & 0.08 & $2.57_{\mathrm{ab}}$ & 0.10 & $1.68_{\mathrm{ab}}$ & 0.03 \\
\hline \multicolumn{9}{|c|}{ Peer victimization } \\
\hline Grades 6-8 & $2.17_{\mathrm{a}}$ & 0.11 & $1.68_{\mathrm{ab}}$ & 0.06 & $2.26_{b}$ & 0.08 & $1.50_{\mathrm{ab}}$ & 0.02 \\
\hline Grade 8 & $2.26_{\mathrm{ac}}$ & 0.14 & $1.51_{\mathrm{ab}}$ & 0.06 & $2.15_{\mathrm{bd}}$ & 0.08 & $1.47_{\mathrm{cd}}$ & 0.02 \\
\hline \multicolumn{9}{|c|}{ Parent-child rel. qual. } \\
\hline Grades 6-8 & $3.21_{\mathrm{a}}$ & 0.15 & $3.20_{\mathrm{ab}}$ & 0.09 & $3.80_{\mathrm{b}}$ & 0.09 & $4.07_{\mathrm{ab}}$ & 0.03 \\
\hline Grade 8 & $2.99_{\mathrm{ac}}$ & 0.20 & $3.82_{\mathrm{ab}}$ & 0.09 & $3.12_{\mathrm{bd}}$ & 0.09 & $4.00_{\mathrm{cd}}$ & 0.04 \\
\hline \multicolumn{9}{|c|}{ Friendship qual. } \\
\hline Grades 6-8 & $3.63_{\mathrm{a}}$ & 0.11 & $3.78_{b}$ & 0.07 & $3.48_{\mathrm{bc}}$ & 0.08 & $3.91_{\mathrm{ac}}$ & 0.03 \\
\hline Grade 8 & $3.49_{\mathrm{ac}}$ & 0.15 & $3.96_{\mathrm{ab}}$ & 0.07 & $3.56_{\mathrm{bd}}$ & 0.10 & $3.97_{\mathrm{cd}}$ & 0.03 \\
\hline
\end{tabular}

Note: rel. qual., relationship quality. All variables ranged from 1 to 5 . Similar subscripts denote significant $(p<.036$; corrected for multiple testing using the method described by Benjamini \& Hochberg, 1995) mean level differences between classes.

${ }^{a}$ Similar subscripts denote marginally significant $(p<.074$; equal to $p<0.10$ but corrected for multiple testing using the method described by Benjamini \& Hochberg, 1995) mean level differences between classes. 
were characterized by higher anxious solitude than youth with stable low anxiety.

In contrast, the middle school transition was associated with discontinuity in anxiety trajectories for a minority of youth (19\%), who showed either strongly increasing or decreasing levels of anxiety after the transition in early adolescence. Although levels of anxious solitude in middle childhood did not distinguish these subgroups of youth from each other, their strongly diverging anxiety trajectories were significantly associated with perceived qualities of youths' social contexts (i.e., stressful vs. supportive) during middle school from early to middle adolescence; youth with increasing levels of anxiety after the transition reported more transition-related stressors and poorer quality relationships with friends and parents than youth with decreasing levels of anxiety after the transition.

Overall, our findings suggest that the middle school transition has the potential to alter developmental trajectories of anxiety for some youth, either for better or for worse, although the majority of youth appeared to show continuity in their anxiety trajectories from middle childhood to middle adolescence. Furthermore, youths' individual vulnerability to anxiety partially distinguished those who start along different anxiety trajectories in middle childhood, whereas perceived qualities of youths' social contexts partially distinguished those who progress along different anxiety trajectories after the middle school transition.

\section{Youth anxiety trajectories and the middle school transition}

Despite the traditional view of the middle school transition as a stressful time for youth (Simmons \& Blyth, 1987) that coincides with the start of rapid biological, psychological, cognitive, and social changes associated with the transition from childhood to adolescence, our findings suggested that the middle school transition was not associated with (temporary) increases in anxiety for the majority of youth. In fact, global levels of anxiety tended to gradually decrease as youth grew older, in line with past research (e.g., Olatunji \& Cole, 2009; Van Oort et al., 2009), and only a small minority of youth (5\%) showed increasing anxiety symptoms after the middle school transition. Rather, the middle school transition appeared to be a turning point (Graber \& Brooks-Gunn, 1996; Rutter, 1996; Seidman \& French, 2004), reflecting a time of environmental stress or opportunity (as suggested by Shell et al., 2014) that could alter anxiety trajectories for better or for worse in some youth. This pattern of findings is in line with the idea that youth vary in the degree to which they are affected by experiences or changes in their environments (e.g., an important premise of the differential susceptibility hypothesis; Belsky, Bakermans-Kranenburg, \& van IJzendoorn, 2007). Moreover, the findings support theoretical perspectives on continuity and change in youth psychopathology (Cicchetti \& Rogosch, 1996, 2002) and specifically anxiety (Muris, 2006; Vasey \& Dadds, 2001; Weems, 2008), which suggest that the trajectories followed by youth across development are affected by several factors within the individual and their (social) environment.

Of note, this study revealed both continuity and discontinuity in youths' anxiety trajectories from middle childhood to middle adolescence. Regarding continuity, the majority of youth in our study appeared to show strong stability in their anxiety levels (either high or low) from middle childhood to middle adolescence. There are several possible explanations for this continuity across development. A continuum model of personality traits and problem behavior (i.e., spectrum model; Krueger \& Tackett, 2003) may account for this strong stability, as anxiety appears to show more traitlike than statelike qualities and may be more akin to personality traits than temporary states (e.g., Hale, Klimstra, \& Meeus, 2010; Prenoveau et al., 2011; Widiger, Verheul, \& Van den Brink, 1999). In addition, the accentuation principle (Graber \& BrooksGunn, 1996; Rutter, 1996) suggests that changing circumstances such as transitions or times of major developmental change (e.g., the middle school transition or the entire adolescent period) may accentuate or exaggerate psychological features already present and hence promote continuity in developmental trajectories. Furthermore, individuals are known to select or shape their environment based on individual characteristics; this process is also likely to promote experiences that continue to foster these individual characteristics (Caspi, Elder, \& Bem, 1988; Rutter, 1996). For example, youth with persistent high levels of anxiety reported experiencing more contextual stressors and less social support. It could be that these youth elicit negative experiences because of their anxiety symptoms and/or that they perceive the middle school transition as more stressful and relationships as less supportive because of certain cognitive biases (Muris, 2006; Vasey \& Dadds, 2001) and/or that they react to these negative experiences in ways that maintain their anxiety symptoms.

However, anxiety trajectories of approximately $20 \%$ of youth did show substantial change from early to middle adolescence, suggesting that levels of youth anxiety are not necessarily fixed. For this minority of youth, the middle school transition appeared to have a substantial impact on their anxiety trajectories, considering that after fifth grade youth in the increasing after transition anxiety trajectory experienced an average increase in anxiety symptoms of 8.9 points on a 28-point scale $(32 \%)$ and youth in the decreasing after transition anxiety trajectory experienced an average decrease in anxiety symptoms of 9.4 points on a 28 -point scale (34\%). Thus, although this transition was a time of vulnerability for some youth, it appeared to provide a window of opportunity for other youth (Graber \& Brooks-Gunn, 1996; Rutter, 1996; Shell et al., 2014).

Altogether, the principles of multifinality and equifinality central to the developmental psychopathology perspective (Cicchetti \& Rogosch, 1996, 2002) are well illustrated by the four anxiety trajectories in our study (see Figure 1). Specifically, whereas youth in the persistent low and the decreasing anxiety trajectories showed very different initial levels of anxiety in middle childhood (second grade), these youth 
showed quite similar low levels of anxiety in middle adolescence (eighth grade), illustrating the principle of equifinality. In contrast, whereas youth in the persistent high and decreasing anxiety trajectories showed quite similar initial levels of anxiety in middle childhood (second grade), these youth showed very different levels of anxiety in middle adolescence (eighth grade), illustrating the principle of multifinality. Furthermore, even though youth in the persistent high and increasing anxiety trajectories showed quite similar levels of anxiety in both middle childhood (second grade) and middle adolescence (eighth grade), these youth showed quite different levels of anxiety in between these points in time. Hence, our findings illustrate the importance of delineating the exact anxiety trajectories that youth follow, because youths' level of anxiety at any point in time should be considered within the context of how that level of anxiety has evolved over the course of development (Cicchetti \& Rogosch, 2002).

At the same time, principles of equifinality and multifinality go beyond descriptive illustrations of developmental trajectories, which make these principles still important to consider for youth who follow quite stable anxiety trajectories from middle childhood to middle adolescence. Not only may different processes result in youth following similar anxiety trajectories (i.e., equifinality), but similar anxiety trajectories even over a longer time period may not necessarily result in the same (mal)adaptive outcome for all youth (i.e., multifinality). Therefore, it is important to acknowledge that even for youth who appear to show very similar anxiety trajectories, the associated etiological factors, developmental processes, maintaining mechanisms, and outcomes may be quite different.

\section{Gender differences in youth anxiety trajectories}

Overall, we found gender differences in line with previous studies (for a systematic review of gender differences across the life span, see McLean \& Anderson, 2009) suggesting that girls report somewhat higher anxiety symptoms than boys (although differences in middle childhood were only marginally significant) and are more likely than boys to report stable high or increasing levels of anxiety over time. Exploratory multiple-group GMM analyses, allowing for differences between boys and girls in the number and the shape of the anxiety trajectories, suggested the same number of anxiety trajectories with a similar shape for both boys and girls and similar to results from our total-sample GMM analyses. Therefore, whereas girls tended to report slightly higher levels of anxiety than boys and the proportion of girls in the increasing and particularly the persistent high anxiety trajectories was higher than the proportion of boys, boys and girls show a similar pattern of individual differences in anxiety trajectories across the middle school transition.

\section{Individual vulnerability and youth anxiety trajectories}

Teacher reports of youths' anxious solitude, an affective-behavioral profile that represents an individual vulnerability to general anxiety (Gazelle \& Rubin, 2010), in middle childhood significantly distinguished between youth with high versus low initial levels of anxiety in second grade. Specifically, youth in the persistent high and decreasing anxiety trajectories showed higher individual vulnerability to anxiety in middle childhood than youth in the persistent low trajectory, in line with suggestions that individual vulnerability to anxiety plays an important role in early levels of anxiety (Biederman et al., 1995; Hirshfeld-Becker et al., 2004; Lonigan et al., 2011; Rosenbaum et al., 1993). Even though youth in the increasing anxiety trajectory did not significantly differ from all other youth with respect to their individual vulnerability to anxious solitude in second grade (these youth appeared to be characterized by somewhat moderate levels of anxious solitude), they did show higher levels of anxiety symptoms in second grade than youth in the persistent low trajectory. This pattern of findings may suggest that the initially moderate individual vulnerability to anxiety for youth in the increasing anxiety trajectory grew over time, or that this vulnerability was exacerbated by stressful school, peer, and family contexts after the middle school transition.

\section{Contextual stressors and youth anxiety trajectories}

In line with the abundant evidence suggesting strong associations between anxiety and functioning in educational (Ialongo et al., 1995; Seipp, 1991) and social contexts (Bögels \& Brechman-Toussaint, 2006; Kingery et al., 2010), anxiety trajectories after the middle school transition from early to middle adolescence appeared to be strongly linked to youths' experiences in these contexts during and after the transition. Specifically, youth who showed initially moderate individual vulnerability to anxiety in middle childhood who experienced stressful school, peer, and family contexts after the transition showed strongly increasing anxiety trajectories from early to middle adolescence. These findings suggest that these youth were confronted with transition-related stressors and/or limited support from friends and parents, which were associated with increases in anxiety symptoms after the middle school transition. At the same time, youth who showed individual vulnerability to anxiety in middle childhood but who experienced more positive or supportive experiences in these contexts after the transition showed strongly decreasing anxiety trajectories from early to middle adolescence. Therefore, even though these youth started out with higher anxiety symptoms, they were confronted with few transition-related stressors along with high support from their friends and parents. For these youth, the middle school transition appeared to create opportunities for better adjustment, allowing them to recover across this transition. Finally, some youth with both an individual vulnerability to anxiety in middle childhood and stressful school, peer, and family contexts after the middle school transition showed persistent high levels of anxiety over time, whereas youth without an individual vulnerability to anxiety in middle childhood and with more positive or supportive experiences in these contexts after the transition showed 
persistent low levels of anxiety over time. Altogether, this pattern of findings highlights the importance of considering both individuals' initial individual vulnerability and their contextual experiences, particularly after a transition period, for a better understanding of individual differences in trajectories of anxiety across development.

\section{Strengths, limitations, and directions for future research}

An important strength of this study is its 7-year prospective longitudinal design in a large community sample of youth, covering the entire period from middle childhood to middle adolescence and specifically focusing on the major life transition from elementary to middle school. In addition, our person-centered longitudinal approach allowed for a nuanced exploration of the potential impact of the middle school transition on important theorized individual differences in anxiety symptom development. Finally, by conceptualizing youth anxiety trajectories as distinguished by both initial individual vulnerability and perceived qualities of youths' social contexts (i.e., stressful vs. supportive) across the middle school transition, our study provides support for several important developmental frameworks specific to anxiety symptom development (e.g., Muris, 2006; Vasey \& Dadds, 2001; Weems, 2008) as well as to developmental psychopathology more generally (Cicchetti \& Rogosch, 1996, 2002).

We should also note some limitations of the current study, which may provide important suggestions for future research. Our correlational design does not allow for any causal conclusions, but only allows for inferences about the interrelationship between anxiety symptoms and youths' individual vulnerability and perceived qualities of their social contexts. Because assessment of all constructs was across the same period of time, findings in our study merely allow for the differentiation of youth anxiety trajectories by both individual vulnerability and perceived social contextual factors. Furthermore, we need to acknowledge both directions of effects in associations between anxiety symptoms and perceived qualities of youths' social contexts. Not only may perceived contextual stressors or social support affect youths' anxiety trajectories, but youths' anxiety trajectories may also affect qualities or perceptions of youths' social contexts. A crosslagged panel design would be an appropriate statistical approach to examine the nature of such transactional processes. In addition, it is important to acknowledge that our study design was limited by not taking into account pretransition differences between youth in their perceived social contexts, most of which were assessed only following the transition, which may affect posttransition differences between youth. An important direction for future research would thus be to account for pretransition differences in youths' social contexts when examining how youth with different anxiety trajectories differ posttransition. However, it is important that provisional post hoc analyses suggested a similar pattern of findings correcting for pretransition transition differences in perceived peer victimization, suggesting that posttransition differences between youth in the different anxiety trajectories were not simply reflecting pretransition differences between these youth.

Because of the descriptive nature of this study, we can only speculate how or why the middle school transition might create opportunities for better adjustment for some youth (as evidenced by strongly decreasing levels of anxiety after this transition). For example, Shell et al. (2014) suggested that the middle school transition may motivate some youth to take advantage of opportunities for improved peer relations, which may be linked with lower levels of anxiety for these youth after the transition. It is clear that more research is needed to better understand how such a relatively universal transition as the middle school transition may provide opportunities for improved adjustment for some youth. Focus should be on elucidating factors or processes that may explain different degrees of susceptibility to change associated with transitions (i.e., why are anxiety trajectories of some youth altered by this transition whereas anxiety trajectories of other youth remain relatively stable?).

Future research should also provide more insight into factors or processes that may predict or explain why some youth experience more supportive or less stressful environments across the middle school transition than others, and through what mechanisms these experiences are associated with increasing or decreasing levels of anxiety after the transition. An interesting analytical approach for future research concerning developmental trajectories across transition points, including studies on anxiety symptom development across the middle school transition, is latent transition growth mixture modeling (see, e.g., Petras, Masyn, \& Ialongo, 2011). By capturing developmental trajectories before and after a transition point in two separate GMMs and using latent transition analysis to model stability and change in trajectory classes across the transition, this approach describes individual differences in development across transition points. Correlates of the transition probabilities can be included in subsequent analyses to gain important insights into moderating variables or mediating processes (i.e., addressing "the how or why" associated with developmental trajectories across transition points).

Furthermore, with the exception of teacher reports of anxious solitude at the start of the study in second grade, we relied exclusively on youth self-reports of their anxiety symptoms and their social contexts. While youth may be better judges of their own anxiety symptoms than, for example, parents (Cosi, Canals, Hernández-Martinez, \& Vigil-Colet, 2010), multi-informant assessments may be particularly important in providing additional information on associations between youth anxiety development and other psychosocial factors. Although our results are limited to youths' perceptions, youths' perceptions of their environment or psychosocial adjustment have been suggested to be of equal, or perhaps even more, importance to their mental health than more "objective" judgments. For example, Ialongo, Edelsohn, and Kellam (2001) found that young children's self-reported depressed mood was related to a wider range of long-terms outcomes, including 
academic performance, psychological well-being, and mental health service need and use, than parent-reported child depressed mood, particularly for girls, attesting to the predictive validity of youth self-reports. Furthermore, youths' perceptions of their environment may be affected by their level of anxiety symptoms. For future investigations, it would thus be important to include multiple-method, multiple-informant assessments to address potential inflation of associations due to shared method variance and to provide additional information regarding youth anxiety development and its associations with individual vulnerability and social contextual factors.

In addition, the present study did not take into account youths' pubertal status or timing, which have been linked with elevated anxiety, particularly among girls (Reardon, Leen-Feldner, \& Hayward, 2009). In future research, it would therefore be important to distinguish the extent to which increases in anxiety for some youth after the middle school transition are associated with pubertal changes versus transition-related experiences, or both. Pubertal changes may, for example, contribute to more positive or negative experiences across the school transition, depending in part on whether or not the middle school transition coincides with pubertal change. Alternatively, pubertal status or timing may directly contribute to anxiety, which could then determine transition-related experiences. Future research should aim to provide more insight into the role of pubertal status and timing in both anxiety symptoms and stressful versus supportive experiences across and after the middle school transition, particularly for girls (Reardon et al., 2009).

Finally, this study focused on anxiety symptoms as representing one global anxiety construct. Theories (Warren \& Sroufe, 2004; Weems, 2008; Westenberg, Siebelink, \& Treffers, 2001) and empirical findings (e.g., Hale et al., 2008; Nelemans et al., 2014; Van Oort et al., 2009; Weems \& Costa, 2005) emphasize important age-related developmental changes in the expression of anxiety, especially during adolescence. Though a different phenotypic/genetic structure of anxiety in childhood (more global and one dimensional) and adolescence (more specific and multidimensional) has been suggested (Waszczuk, Zavos, Gregory, \& Eley, 2014), future studies may want to examine the potential differential impact of the middle school transition on developmental trajectories of more specific forms of anxiety (e.g., generalized anxiety or social anxiety symptoms). Furthermore, the examination of joint trajectories of symptoms of anxiety and depression across the middle school transition would be an important direction to incorporate in future research.

\section{Conclusion}

Altogether, this research indicates that youth do not form a homogenous group with respect to their anxiety development from middle childhood to middle adolescence. Moreover, the middle school transition appears to be a potential breakpoint for development for some youth, rather than a stressful life transition for all. Specifically, whereas a majority of youth show relatively stable levels of either high or low anxiety from middle childhood to middle adolescence, other youth may show strongly increasing or decreasing anxiety after the middle school transition. Consistent with developmental psychopathology theories that emphasize the interplay between personal and social-contextual risk and protective factors in determining the specific developmental trajectories followed by youth, individual differences in youth anxiety trajectories are distinguished by a combination of individual vulnerability to anxiety as well as the degree of perceived transition-related stress. This complex interplay resulted in continuity or discontinuity in certain anxiety trajectories, with contextual factors after the middle school transition seemingly impacting anxiety trajectories of some youth in a for-better or for-worse manner.

\section{References}

Adams, G. R., \& Berzonsky, M. (Eds.). (2005). Blackwell handbook of adolescence. New York: Wiley.

Allan, N. P., Capron, D. W., Lejuez, C. W., Reynolds, E. K., MacPherson, L., \& Schmidt, N. B. (2014). Developmental trajectories of anxiety symptoms in early adolescence: The influence of anxiety sensitivity. Journal of Abnormal Child Psychology, 42, 589-600. doi:10.1007/s10802-013-9806-0

Armsden, G. C., \& Greenberg, M. T. (1987). The inventory of parent and peer attachment: Individual differences and their relationship to psychological well-being in adolescence. Journal of Youth and Adolescence, 16, 427-454. doi:10.1007/bf02202939

Asparouhov, T., \& Muthén, B. (2014). Auxiliary variables in mixture modeling: Three-step approaches using Mplus. Structural Equation Modeling, 21, 329-341. doi:10.1080/10705511.2014.915181

Barlow, D. H. (2002). Anxiety and its disorders: The nature and treatment of anxiety and Panic (2nd ed.). New York: Guilford Press.

Belsky, J., Bakermans-Kranenburg, M. J., \& van IJzendoorn, M. H. (2007). For better and for worse: Differential susceptibility to environmental influences. Current Directions in Psychological Science, 16, 300-304. doi:10.1111/j.1467-8721.2007.00525.X

Benjamini, Y., \& Hochberg, Y. (1995). Controlling the false discovery rate: A practical and powerful approach to multiple testing. Journal of the Royal Statistical Society. Series B, 57, 289-300.
Biederman, J., Rosenbaum, J. F., Chaloff, J., \& Kagan, J. (1995). Behavioural inhibition as a risk factor for anxiety disorders. In J. S. March (Ed.), Anxiety disorders in children and adolescents (pp. 61-81). New York: Guilford Press.

Bögels, S. M., \& Brechman-Toussaint, M. L. (2006). Family issues in child anxiety: Attachment, family functioning, parental rearing and beliefs. Clinical Psychology Review, 26, 834-856. doi:10.1016/j.cpr.2005. 08.001

Bollmer, J. M., Harris, M. J., \& Milich, R. (2006). Reactions to bullying and peer victimization: Narratives, physiological arousal, and personality. Journal of Research in Personality, 40, 803-828. doi:10.1016/j.jrp. 2005.09.003

Bosquet, M., \& Egeland, B. (2006). The development and maintenance of anxiety symptoms from infancy through adolescence in a longitudinal sample. Development and Psychopathology, 18, 517-550. doi:10.1017/ S0954579406060275

Broeren, S., Muris, P., Diamantopoulou, S., \& Baker, J. R. (2013). The course of childhood anxiety symptoms: Developmental trajectories and child-related factors in normal children. Journal of Abnormal Child Psychology, 41, 81-95. doi:10.1007/s10802-012-9669-9

Brown, B. B., \& Larson, J. (2009). Peer relationships in adolescence. In R. M. Lerner \& L. Steinberg (Eds.), Handbook of adolescent psychology: 
Vol. 2. Contextual influences on adolescent development (3rd ed., pp. 74103). Hoboken, NJ: Wiley.

Calkins, S. D., \& Fox, N. A. (2002). Self-regulatory processes in early personality development: A multilevel approach to the study of childhood social withdrawal and aggression. Development and Psychopathology, 14, 477-498. doi:10.1017.S095457940200305X

Caspi, A., Elder, G. H., \& Bem, D. J. (1988). Moving away from the world: Life-course patterns of shy children. Developmental Psychology, 24, 824-831. doi:10.1037/0012-1649.24.6.824

Cicchetti, D., \& Rogosch, F. A. (1996). Equifinality and multifinality in developmental psychopathology. Development and Psychopathology, 8, 597-600. doi:10.1017/S0954579400007318

Cicchetti, D., \& Rogosch, F. A. (2002). A developmental psychopathology perspective on adolescence. Journal of Consulting and Clinical Psychology, 70, 6-20. doi:10.1037//0022-006X.70.1.6

Cosi, S., Canals, J., Hernández-Martinez, C., \& Vigil-Colet, A. (2010). Parent-child agreement in SCARED and its relationship to anxiety symptoms. Journal of Anxiety Disorders, 24, 129-133. doi:10.1016/j.janxdis.2009.09.008

Costello, E. J., Mustillo, S., Erkanli, A., Keeler, G., \& Angold, A. (2003). Prevalence and development of psychiatric disorders in childhood and adolescence. Archives of General Psychiatry, 60, 837-844. doi:10.1001/archpsyc.60.8.837

Crick, N. R., \& Grotpeter, J. K. (1996). Children's treatment by peers: Victims of relational and overt aggression. Development and Psychopathology, 8, 367-380. doi:10.1017/s0954579400007148

Duchesne, S., Larose, S., Vitaro, F., \& Tremblay, R. E. (2010). Trajectories of anxiety in a population sample of children: Clarifying the role of children's behavioral characteristics and maternal parenting. Development and Psychopathology, 22, 361-373. doi:10.1017/S0954579410000118

Feng, X., Shaw, D. S., \& Silk, J. S. (2008). Developmental trajectories of anxiety symptoms among boys across early and middle childhood. Journal of Abnormal Psychology, 117, 32-47. doi:10.1037/0021-843X.117.1.32

Garnefski, N., \& Diekstra, R. F. W. (1996). Perceived social support from family, school, and peers: Relationship with emotional and behavioral problems among adolescents. Journal of the American Academy of Child \& Adolescent Psychiatry, 35, 1657-1664. doi:10.1097/00004583199612000-00018

Gazelle, H., \& Ladd, G. W. (2003). Anxious solitude and peer exclusion: A diathesis-stress model of internalizing trajectories in childhood. Child Development, 74, 257-278. doi:10.1111/1467-8624.00534

Gazelle, H., Putallaz, M., Li, Y., Grimes, C. L., Kupersmidt, J. B., \& Coie, J. D. (2005). Anxious solitude across contexts: Girls' interactions with familiar and unfamiliar peers. Child Development, 76, 227-246. doi:10.1111/j.1467-8624.2005.00841.x

Gazelle, H., \& Rubin, K. H. (2010). Social anxiety in childhood: Bridging developmental and clinical perspectives. New Directions for Child and Adolescent Development, 127, 1-16.

Gazelle, H., Workman, J. O., \& Allan, W. (2010). Anxious solitude and clinical disorder in middle childhood: Bridging developmental and clinical approaches to childhood social anxiety. Journal of Abnormal Child Psychology, 38, 1-17. doi:10.1007/s10802-009-9343-Z

Graber, J. A., \& Brooks-Gunn, J. (1996). Transitions and turning points: Navigating the passage from childhood through adolescence. Developmental Psychology, 32, 768-776. doi:10.1037/0012-1649.32.4.768

Graham, S., \& Juvonen, J. (1998). Self-blame and peer victimization in middle school: An attributional analysis. Developmental Psychology, 34, 587-599. doi:10.1037/0012-1649.34.3.587

Hale, W. W., III, Klimstra, T. A., \& Meeus, W. H. J. (2010). Is the generalized anxiety disorder symptom of worry just another form of neuroticism? A five-year longitudinal study of adolescents from the general population. Journal of Clinical Psychiatry, 71, 942-948. doi:10.4088/jcp. 09m05506blu

Hale, W. W., III, Raaijmakers, Q. A. W., Muris, P., Van Hoof, A., \& Meeus, W. H. J. (2008). Developmental trajectories of adolescent anxiety disorder symptoms: A 5-year prospective community study. Journal of the American Academy of Child \& Adolescent Psychiatry, 47, 556-564. doi:10.1097/CHI.0b013e3181676583

Helsen, M., Vollebergh, W. A. M., \& Meeus, W. H. J. (2000). Social support from parents and friends and emotional problems in adolescence. Journal of Youth and Adolescence, 29, 319-335. doi:10.1023/A:1005147708827

Hirshfeld-Becker, D. R., Biederman, J., \& Rosenbaum, J. F. (2004). Behavioral inhibition. In T. L. Morris, \& J. S. March (Eds.), Anxiety disorders in children and adolescents (pp. 27-58). New York: Guilford Press.
Ialongo, N., Edelsohn, G., \& Kellam, S. (2001). A further look at the prognostic power of young children's reports of depressed mood and feelings. Child Development, 72, 736-747. doi:10.1111/1467-8624.00312

Ialongo, N., Edelsohn, G., Werthamer-Larsson, L., Crockett, L., \& Kellam, S. (1995). The significance of self-reported anxious symptoms in first grade children: Prediction to anxious symptoms and adaptive functioning in fifth grade. Journal of Child Psychology and Psychiatry, 36, 427-437. doi:10.1111/j.1469-7610.1995.tb01300.x

Jung, T., \& Wickrama, K. A. S. (2008). An introduction to latent class growth analysis and growth mixture modeling. Social and Personality Psychology Compass, 2, 302-317. doi:10.1111/j.1751-9004.2007.00054.x

Kagan, J., Reznick, J. S., \& Gibbons, J. (1989). Inhibited and uninhibited types of children. Child Development, 60, 838-845. doi:10.2307/ 1131025

Kingery, J. N., Erdley, C. A., Marshall, K. C., Whitaker, K. G., \& Reuter, T. R. (2010). Peer experiences of anxious and socially withdrawn youth: An integrative review of the developmental and clinical literature. Clinical Child and Family Psychology Review, 13, 91-128. doi:10.1007/ s10567-009-0063-2

Krueger, R. F., \& Tackett, J. L. (2003). Personality and psychopathology: Working toward the bigger picture. Journal of Personality Disorders, 17, 109-128. doi:10.1521/pedi.17.2.109.23986

Laursen, B., \& Collins, A. W. (2009). Parent-adolescent relationships during adolescence. In R. M. Lerner \& L. Steinberg (Eds.), Handbook of adolescent psychology (3rd ed., Vol. 2, pp. 3-42). Hoboken, NJ: Wiley.

Letcher, P., Sanson, A., Smart, D., \& Toumbourou, J. W. (2012). Precursors and correlates of anxiety trajectories from late childhood to late adolescence. Journal of Clinical Child and Adolescent Psychology, 41, 417432. doi:10.1080/15374416.2012.680189

Lonigan, C. J., Philips, B. M., Wilson, S. B., \& Allan, N. P. (2011). Temperament and anxiety in children and adolescents. In W. K. Silverman \& A. P. Field (Eds.), Anxiety disorders in children and adolescents (2nd ed., pp. 198-226). Cambridge: Cambridge University Press.

McLean, C. P., \& Anderson, E. R. (2009). Brave men and timid women? A review of the gender differences in fear and anxiety. Clinical Psychology Review, 29, 496-505. doi:10.1016/j.cpr.2009.05.003

Merikangas, K. R., He, J.-P., Burstein, M., Swanson, S. A., Avenevoli, S., Cui, L., . . Swendsen, J. (2010). Lifetime prevalence of mental disorders in U.S. adolescents: Results from the national comorbidity survey replication-adolescent supplement (NCS-A). Journal of the American Academy of Child \& Adolescent Psychiatry, 49, 980-989. doi:10.1016/ j.jaac.2010.05.017

Morin, A. J. S., Maïano, C., Nagengast, B., Marsh, H. W., Morizot, J., \& Janosz, M. (2011). General growth mixture analysis of adolescents developmental trajectories of anxiety: The impact of untested invariance assumptions on substantive interpretations. Structural Equation Modeling, 18, 613-648. doi:10.1080/10705511.2011.607714

Muris, P. (2006). The pathogenesis of childhood anxiety disorders: Considerations from a developmental psychopathology perspective. International Journal of Behavioral Development, 30, 5-11. doi:10.1177/ 0165025406059967

Muris, P., Merckelbach, H., Ollendick, T., King, N., \& Bogie, N. (2002). Three traditional and three new childhood anxiety questionnaires: Their reliability and validity in a normal adolescent sample. Behaviour Research and Therapy, 40, 753-772. doi:10.1016/S0005-7967(01)00056-0

Muthén, L. K., \& Muthén, B. O. (1998-2015). Mplus user's guide (7th ed.). Los Angeles: Author.

Nagin, D. S. (2005). Group based modeling of development. Cambridge, MA: Harvard University Press.

Nelemans, S. A., Hale, W. W., III, Branje, S. J. T., Raaijmakers, Q. A. W., Frijns, T., Van Lier, P. A. C., \& Meeus, W. H. J. (2014). Heterogeneity in development of adolescent anxiety disorder symptoms in an 8-year longitudinal community study. Development and Psychopathology, 26, 181-202. doi:10.1017/S0954579413000503

Oh, W., Rubin, K. H., Bowker, J. C., Booth-LaForce, C., Rose-Krasnor, L., \& Laursen, B. (2008). Trajectories of social withdrawal from middle childhood to early adolescence. Journal of Abnormal Child Psychology, 36, 553-566. doi:10.1007/s10802-007-9199-z

Olatunji, B. O., \& Cole, D. A. (2009). The longitudinal structure of general and specific anxiety dimensions in children: Testing a latent trait-state-occasion model. Psychological Assessment, 21, 412-424. doi:10.1037/ a0016206

Petras, H., Masyn, K., \& Ialongo, N. (2011). The developmental impact of two first grade preventive interventions on aggressive/disruptive behavior 
in childhood and adolescence: An application of latent transition growth mixture modeling. Prevention Science, 12, 300-313. doi:10.1007/ s11121-011-0216-7

Prenoveau, J. M., Craske, M. G., Zinbarg, R. E., Mineka, S., Rose, R. D., \& Griffith, J. W. (2011). Are anxiety and depression just as stable as personality during late adolescence? Results from a three-year longitudinal latent variable study. Journal of Abnormal Psychology, 120, 832-843. doi:10.1037/a0023939

Prinzie, P., Van Harten, L. V., Deković, M., Van den Akker, A. L., \& Shiner, R. L. (2014). Developmental trajectories of anxious and depressive problems during the transition from childhood to adolescence: Personality $x$ Parenting interactions. Development and Psychopathology, 26, 10771092. doi: $10.1017 /$ S0954579414000510

Rapee, R. M. (2002). The development and modification of temperamental risk for anxiety disorders: Prevention of a lifetime of anxiety? Biological Psychiatry, 52, 947-957. doi:10.1016/S0006-3223(02)01572-X

Reardon, L. E., Leen-Feldner, E. W., \& Hayward, C. (2009). A critical review of the empirical literature on the relation between anxiety and puberty. Clinical Psychology Review, 29, 1-23. doi:10.1016/j.cpr.2008.09.005

Reinecke, J. (2006). Longitudinal analysis of adolescents' deviant and delinquent behavior: Applications of latent class growth curves and growth mixture models. Methodology, 2, 100-112. doi:10.1027/1614-2241.2.3.100

Reynolds, C. R., \& Paget, K. D. (1981). Factor analysis of the Revised Children's Manifest Anxiety Scale for Blacks, Whites, Males, and Females with a national normative sample. Journal of Consulting and Clinical Psychology, 49, 352-359. doi:10.1037//0022-006X.49.3.352

Reynolds, C. R., \& Richmond, B. O. (1979). Factor structure and construct validity of "what I think and feel": The Revised Children's Manifest Anxiety Scale. Journal of Personality Assessment, 43, 281-283. doi:10.1207/ s15327752jpa4303_9

Ridenour, T. A., Greenberg, M. T., \& Cook, E. T. (2006). Structure and validity of people in my life: A self-report measure of attachment in late childhood. Journal of Youth and Adolescence, 35, 1037-1053. doi:10. 1007/s10964-006-9070-5

Robinson, N. S., Garber, J., \& Hilsman, R. (1995). Cognitions and stress: Direct and moderating effects on depressive versus externalizing symptoms during the junior high school transition. Journal of Abnormal Psychology, 104, 453-463. doi:10.1037/0021-843x.104.3.453

Rosenbaum, J. F., Biederman, J., Bolduc-Murphy, E. A., Faraone, S. V., Chaloff, J., Hirshfeld, D. R., \& Kagan, J. (1993). Behavioral inhibition in childhood: A risk factor for anxiety disorders. Harvard Review of Psychiatry, 1, 2-16. doi:10.3109/10673229309017052

Rubin, K. H., \& Burgess, K. B. (2001). Social withdrawal and anxiety. In M. W. Vasey \& M. R. Dadds (Eds.), The developmental psychopathology of anxiety (pp. 407-434). New York: Oxford University Press. doi:10. 1093/med:psych/9780195123630.003.0018

Rudolph, K. D., Troop-Gordon, W., Hessel, E. T., \& Schmidt, J. D. (2011). A latent growth curve analysis of early and increasing peer victimization as predictors of mental health across elementary school. Journal of Clinical Child and Adolescent Psychology, 40, 111-122. doi:10.1080/15374416. 2011.533413

Rutter, M. (1996). Transitions and turning points in developmental psychopathology: As applied to the age span between childhood and mid-adulthood. International Journal of Behavioral Development, 19, 603-626. doi:10.1177/016502549601900309

Seidman, E., \& French, S. E. (2004). Developmental trajectories and ecological transitions: A two-step procedure to aid in the choice of prevention and promotion interventions. Development and Psychopathology, 16, 1141-1159. doi:10.1017/S0954579404040179

Seipp, B. (1991). Anxiety and academic performance: A meta-analysis of findings. Anxiety Research, 4, 27-41. doi:10.1080/08917779108248762
Seligman, L. D., Ollendick, T. H., Langley, A. K., \& Baldacci, H. B. (2004) The utility of measures of child and adolescent anxiety: A meta-analytic review of the Revised Children's Manifest Anxiety Scale, the State-Trait Anxiety Inventory for Children, and the Child Behavior Checklist. Journal of Clinical Child and Adolescent Psychology, 33, 557-565. doi:10.1207/s15374424jecp3303_13

Shell, M. D., Gazelle, H., \& Faldowski, R. A. (2014). Anxious solitude and the middle school transition: A Diathesis $\times$ Stress model of peer exclusion and victimization trajectories. Developmental Psychology, 50, 15691583. doi: $10.1037 / \mathrm{a} 0035528$

Simmons, R. G., \& Blyth, D. A. (1987). Moving into adolescence: The impact of pubertal change and school context. Hawthorne, NY: Aldine de Gruyter.

Simmons, R., Burgeson, R., Carlton-Ford, S., \& Blyth, D. (1987). The impact of cumulative change in early adolescence. Child Development, 58, 1220-1234. doi:10.2307/1130616

Snyder, J., Bullard, L., Wagener, A., Leong, P. K., Snyder, J., \& Jenkins, M. (2009). Childhood anxiety and depressive symptoms: Trajectories, relationship, and association with subsequent depression. Journal of Clinical Child and Adolescent Psychology, 38, 837-849. doi:10.1080/ 15374410903258959

Stallard, P., Velleman, R., Langsford, J., \& Baldwin, S. (2001). Coping and psychological distress in children involved in road traffic accidents. British Journal of Clinical Psychology, 40, 197-208. doi:10.1348/ 014466501163643

Van Oort, F. V. A., Greaves-Lord, K., Verhulst, F. C., Ormel, J., \& Huizink, A. C. (2009). The developmental course of anxiety symptoms during adolescence: The TRAILS study. Journal of Child Psychology and Psychiatry, 50, 1209-1217. doi:10.1111/j.1469-7610.2009.02092.x

Varela, E. R., \& Biggs, B. K. (2006). Reliability and validity of the Revised Children's Manifest Anxiety Scale (RCMAS) across samples of Mexican, Mexican American, and European American children: A preliminary investigation. Anxiety, Stress, \& Coping, 19, 67-80. doi:10.1080/ 10615800500499727

Vasey, M. W., \& Dadds, M. R. (2001). An introduction to the developmental psychopathology of anxiety. In M. W. Vasey \& M. R. Dadds (Eds.), The developmental psychopathology of anxiety (pp. 3-26). New York: Oxford University Press.

Warren, S. L., \& Sroufe, L. A. (2004). Developmental issues. In T. H. Ollendick \& J. S. March (Eds.), Phobic and anxiety disorders in children and adolescents: A clinician's guide to effective psychosocial and pharmacological interventions (pp. 92-115). New York: Oxford University Press.

Waszczuk, M. A., Zavos, H. M. S., Gregory, A. M., \& Eley, T. C. (2014). The phenotypic and genetic structure of depression and anxiety disorder symptoms in childhood, adolescence, and young adulthood. JAMA Psychiatry, 71, 905-916. doi:10.1001/ jamapsychiatry.2014.655

Weems, C. F. (2008). Developmental trajectories of childhood anxiety: Identifying continuity and change in anxious emotion. Developmental Review, 28, 488-502. doi:10.1016/j.dr.2008.01.001

Weems, C. F., \& Costa, N. M. (2005). Developmental differences in the expression of childhood anxiety symptoms and fears. Journal of the American Academy of Child \& Adolescent Psychiatry, 44, 656-663. doi:10.1097/01.chi.0000162583.25829.4b

Westenberg, P. M., Siebelink, B. M., \& Treffers, P. D. A. (2001). Psychosocial developmental theory in relation to anxiety and its disorders. In W. K. Silverman \& P. D. A. Treffers (Eds.), Anxiety disorders in children and adolescents: Research, assessment and intervention (pp. 72-89). Cambridge: Cambridge University Press.

Widiger, T. A., Verheul, R., \& Van den Brink, W. (1999). Personality and psychopathology. In L. A. Pervin \& O. P. John (Eds.), Handbook of personality: Theory and research. New York: Guilford Press. 